\title{
Docking Studies of Porphyrin-based Photosensitizers on Rhombellanes
}

\author{
(D) Raluca Pop, ${ }^{1, *}$ Mihai Medeleanu2,\# \\ 1 Faculty of Pharmacy, University of Medicine and Pharmacy “Victor Babeş” Timisoara, Eftimie Murgu Square 2, 300041 Timişoara, Romania \\ 2 University Politehnica of Timisoara, Faculty of Industrial Chemistry and Environmental Engineering, C. Telbisz 6, 300001, Timisoara, Romania \\ * Corresponding author's e-mail address: pop.raluca@umft.ro \\ \# Corresponding author's e-mail address: mihai.medeleanu@chim.upt.ro \\ RECEIVED: May 20, 2021 * REVISED: July 5, 2021 * ACCEPTED: July 6, 2021
}

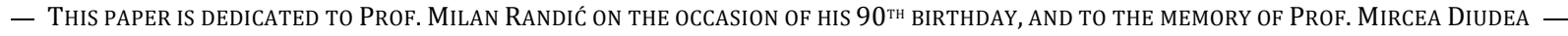

\begin{abstract}
Photodynamic therapy represents an alternative and/or adjuvant method for the treatment of superficial tumors; this way, there is an increased interest regarding the design of new photosensitizers with improved properties. The aim of the paper is to study the interactions among five substituted porphyrins and some rhombellanes (seven cube-rhombellane homeomorphs, C-rbl, with amide structures). The aforementioned porphyrins have been characterized and have been docked to the surface of the rhombellanes; comparisons with the results obtained for fullerene $\mathrm{C}_{60}$ have been performed. The best binding affinities have been obtained for the fluoro-substituted porphyrin docked on the larger rhombellane structures. The results outline that the hydrophobicity of the ligands plays an important role and represents a good indicator of searching for porphyrins with hydrophobic character for future investigations.
\end{abstract}

Keywords: rhombellanes, photodynamic therapy, photosensitizers, porphyrins, molecular docking.

\section{INTRODUCTION}

ANCER is one of the leading causes of morbidity and mortality worldwide. ${ }^{[1]}$ Currently, clinical treatments for cancer include surgery, radiation therapy, chemotherapy, immunotherapy, along with a combination of these strategies.[1] However, these treatments have some important disadvantages, such as myelosuppression, alopecia, and others. Also, surgical resection of certain tumors cannot avoid a high recurrence rate, while the cumulative radiation dose severely limits radiotherapy. This way, together with the research regarding the refinement of conventional anticancer therapy, an increased importance is devoted to the development of some new treatment methods that are safe and cost-effective. ${ }^{[2,3]}$

Photodynamic therapy is a non-invasive method characterized by a low toxicity that is used as an alternative or adjuvant to conventional therapies for the treatment of superficial tumors. ${ }^{[4]}$ The molecular mechanism of photodynamic therapy is based on three components, which produce the desired effects in tissues because of common interactions between a photosensitizer, light with the appropriate wavelength and oxygen. ${ }^{[5,6]}$

Photosensitizers accumulate in significantly higher concentrations in tumor cells than in normal cells. The reason for such biodistribution may be the tendency of the photosensitizers to preferentially combine with lowdensity lipoproteins. The role of low-density lipoproteins is to provide the tissues with the cholesterol needed to create membranes during cell division. The distribution of tumor cells demonstrates an increased absorption of low-density lipoproteins, which act as a "transporter" of the photosensitizer to cancerous tissues. The affinity of photosensitizers for serum lipoproteins, especially for lowdensity lipoproteins, plays an important role in the distribution of these drugs to tumor tissue. ${ }^{[7]}$

Porphyrins and some of their derivatives are widely used as photosensitizers in the photodynamic therapy of cancer. For example, an asymmetric porphyrin has been incorporated into biopolymer films composed of chitosan, polyethylene glycol and gelatin to overcome some of the disadvantages inherent in photosensitizers. ${ }^{[8]}$ 
Most of the clinical applications of porphyrins and metalloporphyrins are due to the macrocyclic aromatic structure. ${ }^{[9]}$ In the free form, it is assumed that only 18 of the $22 \pi$ electrons are conjugated, which are responsible for the characteristic redox and electronic properties. ${ }^{[9]}$

Various systems of porphyrins and nanoparticles have been obtained. During the last years, several gold (III) complexes with strong donor ligands, such as porphyrins, have been reported to have good stability and strong antitumor activity. Of these, tetraphenyl-porphyrin gold (III) $[\mathrm{Au}(\mathrm{TPP})] \mathrm{Cl}$ chloride is physiologically stable, resistant to glutathione, highly cytotoxic to various cancer cell lines, including cisplatin-resistant cancer cells. ${ }^{[10]}$ Other studies have shown that 5,15-diaryl-porphyrins are more effective than the corresponding tetraaryl porphyrins against cancer cell lines and that asymmetric diaryl porphyrins have a higher photodynamic activity than the corresponding symmetrical porphyrins. ${ }^{[11]}$ It is also recognized that amphiphilic photosensitizers exhibit selective tumor absorption and retention. Thus, the photoinduced effects of the photosensitizer with a lipophilic skeleton were studied, as well as a positively charged part, positioned asymmetrically on its molecule. ${ }^{[12]}$ The results suggested that the presence of a positive charge into porphyrins may provide the appropriate degree of amphiphilicity to induce high photodynamic activity; this is confirmed by the fact that cationic molecules are significantly more active than nonpolar derivatives. ${ }^{[13-15]}$

Porphyrin-based photosensitizers, which are usually hydrophobic, can be attached to side chains or encapsulated in the nucleus. In this way, porphyrins can mimic natural heme-containing proteins. ${ }^{[16]}$ Liposomes have been widely used as porphyrin encapsulation systems and they can encapsulate both hydrophobic and hydrophilic materials. The surface of liposomes can be modified with a series of organic and inorganic compounds to obtain a reduced toxicity and an increased therapeutic index. ${ }^{[17,18]}$

The mechanism of PDT consists in excitation of a photosensitizer followed by the transition from its lowest singlet excited state to the lowest triplet excited state. The result is the producing of reactive oxygen species, which leads to the oxidative damage of the targets. ${ }^{[19]}$ The generation of the reactive specie like singlet oxygen $\left({ }^{1} \mathrm{O}_{2}\right)$ is related to the triplet excited state yield. A compound with applications in photodynamic therapy must have the following properties: (1) low HOMO orbital energy (which is an advantage for the electronic transfer); (2) small HOMO-LUMO gap; (3) a stable triplet state; (4) UV-Vis absorption in the range $400-650 \mathrm{~nm} \cdot{ }^{[20]}$

In the field of PDT, carbon-based nanomaterials have attracted a great interest due to properties like thermal conductivity, large surface area and electrical properties. ${ }^{[21]}$
Carbon nanomaterials are mostly used as delivery systems for photosensitizers; the conjugation between nanomaterial and photosensitizer may lead to enhanced stability and selectivity. ${ }^{[22]}$

The present paper aims to investigate the gas-phase interactions among some substituted porphyrins and seven rhombellanes, a new class of compounds proposed by Diudea, ${ }^{[23]}$ at BLYP/DZP level of theory. For comparison, the interactions among porphyrins and fullerene $C_{60}$ are also studied. Zandler and $D^{\prime}$ Souza ${ }^{[24]}$ reported that the B3LYP/321G* computations worked well for describing the geometry, spectral and electrochemical properties of some fullerene-porphyrins conjugates. Wang and $\operatorname{Lin}^{[25]}$ have used the PBE/DZP level of computation for the evaluation of the supramolecular interactions between fullerenes and porphyrins.

The structure of the investigated porphyrins is depicted below:

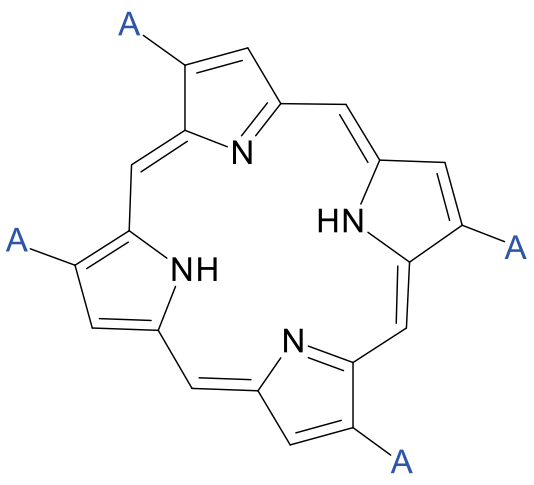

A: $\mathrm{NH}_{2}, \mathrm{OH}, \mathrm{F}, \mathrm{CH}_{2} \mathrm{CH}_{2} \mathrm{OH}$ and $\mathrm{CH}_{2} \mathrm{CH}_{2} \mathrm{NH}_{2}$

\begin{tabular}{|c|c|c|c|c|}
\hline $\mathrm{NH}_{2}$ & $\mathrm{OH}$ & $\mathrm{F}$ & $\mathrm{CH}_{2} \mathrm{CH}_{2} \mathrm{NH}_{2}$ & $\mathrm{CH}_{2} \mathrm{CH}_{2} \mathrm{OH}$ \\
\hline PHR_I & PHR_II & PHR_III & PHR_IV & PHR_V \\
\hline
\end{tabular}

For comparison, the properties of the unsubstituted porphyrin (PHR) have been also computed.

\section{THEORETICAL SECTION}

The structures of the substituted porphyrins have been optimized at BLYP/DZP level of theory, the vibrational analysis proving that true minima have been obtained. For the rhombellane structures and fullerene $C_{60}$, a single point computation has been performed at the same level of theory BLYP/DZP. The geometry optimization, the vibrational analysis and the single point computations have been performed by means of ADF 2014. ${ }^{[26]}$ Also, the energies of the HOMO and LUMO orbitals, the polarizability, ${ }^{[27,28]}$ and the dipole moment have been computed by means of ADF software, ${ }^{[26]}$ at BLYP/DZP level of theory. ${ }^{[29]}$ The descriptors of the molecular shape, ${ }^{[30]}$ namely ovality, Connolly accessible area, Connolly solvent 
excluded volume and the partition coefficient $\log \mathrm{P}$ have been obtained with Chem3D software. Connolly accessible area represents the surface of the compound that is accessible to a solvent; Connolly solvent-excluded volume is the sum of the van der Waals volume and the interstitial volume (small packing defects among the atoms). ${ }^{[31]}$ Ovality measures the degree of deviation from the spheric shape. The same software has been used for the computations of the number of hydrogen bond donors and acceptors, as well as for the topological parameters of the rhombellanes. Autodock Vina ${ }^{[32]}$ has been employed for the docking simulation. The rhombellanes were assigned as receptors and a grid box of $40 \times 40 \times 40 \AA$ was used, the center of the grid box being considered the center of the rhombellanes. The optimized structures of the substituted porphyrins were loaded as ligands and the torsions along the rotatable bonds were assigned. The visualization of the results was also performed by means of AutoDock Vina software. ${ }^{[32]}$ The binding constant $K_{\mathrm{B}}$ has been calculated with the following equation:

$$
K_{B}=e^{-\frac{\Delta G_{B}}{R \cdot T}}
$$

where $\Delta G_{\mathrm{B}}$ is the binding affinity $\left(\mathrm{J} \cdot \mathrm{mol}^{-1}\right), R$ - gas constant $\left(\mathrm{J} \cdot \mathrm{mol}^{-1} \cdot \mathrm{K}^{-1}\right), T$-temperature ( $\left.298 \mathrm{~K}\right)$. In AutoDock Vina, the binding affinities (energies) are computed using the following equation:

$$
\begin{aligned}
\Delta G_{\text {binding }}= & \Delta G_{v d W}+\Delta G_{\text {electronic }}+\Delta G_{H_{-} \text {bonding }}+ \\
& \Delta G_{\text {desolvation }}+\Delta G_{\text {torsion }} .
\end{aligned}
$$

\section{RESULTS AND DISCUSSIONS}

The study is divided in two parts: at first, the characterization of the investigated porphyrins and rhombellanes has been performed. Parameters like the global descriptors of reactivity, electronic, magnetic, and steric properties have been computed. Within the second part, a molecular docking study is performed to evaluate the interactions porphyrins-rhombellanes.

\section{Characterization of the Investigated Porphyrins}

The computed energies of the frontier molecular orbitals show, amongst the investigated compounds, increased values for the fluoro-substituted porphyrin and both hydroxy- and hydroxyethyl-porphyrin. The results are also reflected in the HOMO-LUMO gaps, smaller values being obtained for the amino- and aminoethyl-porphyrins. For comparison, the HOMO and LUMO energies for the unsubstituted porphyrin are -0.209 and $-0.137 \mathrm{H}$, respectively.

Regarding the graphical representation of the frontier molecular orbitals, it has been observed that for amino-porphyrin (PHR_I) the HOMO and LUMO orbitals are delocalized both on the cyclic structure and on the four grafted amino groups. In a lesser extent, the frontier molecular orbitals are delocalized on the hydroxyl groups of PHR_II; also, only the HOMO orbitals appear at one of the amino groups of PHR_IV. For all the other structures, the frontier molecular orbitals appear delocalized only on the porphyrin cycle. The delocalization of the frontier molecular orbitals on the entire structure of PHR_I may be connected with the lower values of the energies depicted in Table 1.

Based on the above-mentioned HOMO-LUMO values, three descriptors of global reactivity have been computed: chemical potential, hardness and electrophilicity.

The lowest value of the chemical potential was obtained for the compound substituted with amino groups;

Table 1. Frontier molecular orbitals energies (BLYP/DZP)

\begin{tabular}{ccccc}
\hline & Compound & $E_{\text {номо }}(\mathrm{H})$ & $E_{\text {LUмо }}(\mathrm{H})$ & HL gap $(\mathrm{eV})$ \\
\hline 1 & PHR_I & -0.166 & -0.106 & 1.632 \\
2 & PHR_II & -0.199 & -0.126 & 1.986 \\
3 & PHR_III & -0.235 & -0.163 & 1.958 \\
4 & PHR_IV & -0.184 & -0.123 & 1.659 \\
5 & PHR_V & -0.202 & -0.129 & 1.985 \\
6 & PHR & -0.209 & -0.137 & 1.958 \\
\hline
\end{tabular}

Table 2. Global descriptors of the reactivity of the studied porphyrins (BLYP/DZP)

\begin{tabular}{ccccc}
\hline & Compound & Chemical potential (eV) & Hardness (eV) & Electrophilicity (eV) \\
\hline 1 & PHR_I & -3.699 & 0.816 & 8.384 \\
2 & PHR_II & -4.420 & 0.993 & 9.837 \\
3 & PHR_III & -5.413 & 0.979 & 14.965 \\
4 & PHR_IV & -4.175 & 0.823 & 10.590 \\
5 & PHR_V & -4.501 & 0.993 & 10.200 \\
6 & PHR & -4.705 & 0.979 & 11.306 \\
\hline
\end{tabular}


Table 3. Singlet-triplet gap (BLYP/DZP)

\begin{tabular}{ccccc}
\hline & Compound & $E$ singlet $(\mathrm{H})$ & $E$ triplet $(\mathrm{H})$ & $\Delta \mathrm{ST}(\mathrm{eV})$ \\
\hline 1 & PHR_I & -320.987 & -319.378 & 1.609 \\
2 & PHR_II & -296.658 & -294.767 & 1.891 \\
3 & PHR_III & -270.421 & -268.585 & 1.836 \\
4 & PHR_IV & -456.489 & -454.543 & 1.946 \\
5 & PHR_V & -433.142 & -431.277 & 1.865 \\
6 & PHR & -271.526 & -269.697 & 1.829 \\
\hline
\end{tabular}

similar values are obtained for hydroxy-porphyrins and hydroxyethyl-porphyrins, while the maximum value of the chemical potential was obtained for the fluoro-substituted compound. The chemical hardness takes values between $0.816 \mathrm{eV}$ (for amino-porphyrin) and 0.993 (for hydroxy- and hydroxyethyl-porphyrin).

The singlet-triplet gap is an important parameter for the compounds with applications in the photodynamic therapy, therefore the energies associated with both singlet and triplet states have been computed. The results are depicted in Table 3; the lowest singlet-triplet gap was obtained for amino-porphyrin, while insignificant differences were recorded for the other four compounds. For comparison, the singlet-triplet gap computed for the unsubstituted porphyrin (PHR) is $1.829 \mathrm{eV}(-271.526 \mathrm{H}$ and -269.697 are the energies of the singlet and triplet states, respectively).

The calculated values of polarizability and dipole moment highlight the similarities between the porphyrins substituted with $\mathrm{OH}, \mathrm{NH}_{2}$ and $\mathrm{F}$ groups. Regarding the partition coefficient, the highest hydrophobicity was obtained for the halogen-substituted compound (PHR_III).

Also, three steric parameters have been computed: Connolly accessible area (CAA), Connolly solvent excluded volume (CSEV) and ovality. PHR_III (when the fluorine atom is present) is characterized by the smallest solvent accessible area, solvent excluded volume and ovality. For comparison, the same parameters have been computed for the unsubstituted porphyrin and the obtained values are $278.511 \AA^{2}, 245.240 \AA^{3}$ and 1.475 , respectively.

\section{Docking Studies}

Rhombellanes are a class of nanostructures proposed by Diudea, ${ }^{[23]}$ with all strong rings being rhombs or squares; some of them have local propellane substructure. Various cube-rhombellanes have been proposed, using functionalized structures like ether core, amide or ester envelope. ${ }^{[33]}$

In this paper, seven rhombellanes with amide envelope and the bridge carbon atoms (from the propellane structure) functionalized with bromine have been employed. They have been used as target macromolecules for the substituted porphyrins; for comparison, the porphyrins were also docked on fullerene $\mathrm{C}_{60}$.

Prior to the docking studies, a short characterization of the proposed rhombellanes has been performed. The seven structures have the number of atoms within the

Table 4. Polarizability, $\log \mathrm{P}$ and dipole moment of the porphyrins I-V and the unsubstituted porphyrin

\begin{tabular}{ccccc}
\hline & Compound & Polarizability & log P & Dipole moment (D) \\
\hline 1 & PHR_I & 90.476 & -4.379 & 0.065 \\
2 & PHR_II & 85.384 & -4.687 & 0.041 \\
3 & PHR_III & 81.381 & 0.496 & 0 \\
4 & PHR_IV & 182.176 & -2.832 & 1.670 \\
5 & PHR_V & 162.525 & -3.232 & 2.940 \\
6 & PHR & 448.83 & 0.524 & 0.009 \\
\hline
\end{tabular}

Table 5. Steric parameters of substituted and un- porphyrins

\begin{tabular}{cccccc}
\hline Compound & CAA $\left(\AA^{2}\right)$ & CSEV $\left(\AA^{3}\right)$ & Ovality & HBA & HBD \\
\hline PHR_I & 328.065 & 290.440 & 1.545 & 8 & 8 \\
PHR_II & 308.890 & 271.373 & 1.524 & 8 & 8 \\
PHR_III & 289.914 & 254.866 & 1.491 & 8 & 4 \\
PHR_IV & 461.463 & 421.463 & 1.697 & 8 & 8 \\
PHR_V & 444.828 & 404.451 & 1.682 & 8 & 8 \\
PHR & 278.511 & 245.240 & 1.475 & 4 & 4 \\
\hline
\end{tabular}


Table 6. Structure specification of the rhombellanes investigated in the present study

\begin{tabular}{cccc}
\hline Structure & Atoms & Molecular formula & TBE/atom (H) \\
\hline C_rbl_CONH_C=C_C & 336 & $\mathrm{C}_{192} \mathrm{H}_{84} \mathrm{Br}_{12} \mathrm{~N}_{24} \mathrm{O}_{24}$ & 0.231 \\
C_rbl_CONH_C=C_B & 336 & $\mathrm{C}_{192} \mathrm{H}_{84} \mathrm{Br}_{12} \mathrm{~N}_{24} \mathrm{O}_{24}$ & 0.230 \\
C_rbl_CONH_C=C_Ar & 312 & $\mathrm{C}_{192} \mathrm{H}_{60} \mathrm{Br}_{12} \mathrm{~N}_{24} \mathrm{O}_{24}$ & 0.193 \\
C_rbl_CONH_3C=C_Ar & 360 & $\mathrm{C}_{240} \mathrm{H}_{60} \mathrm{Br}_{12} \mathrm{~N}_{24} \mathrm{O}_{24}$ & 0.243 \\
C_rbl_CONH_G_B_Coja & 220 & $\mathrm{C}_{68} \mathrm{H}_{84} \mathrm{Br}_{8} \mathrm{~N}_{36} \mathrm{O}_{24}$ & 0.213 \\
C_rbl_CONH_Ar_G_Core & 128 & $\mathrm{C}_{52} \mathrm{H}_{24} \mathrm{Br}_{4} \mathrm{~N}_{12} \mathrm{O}_{36}$ & 0.197 \\
C_rbl_CONH_C_Core & 152 & $\mathrm{C}_{52} \mathrm{H}_{48} \mathrm{Br}_{4} \mathrm{~N}_{12} \mathrm{O}_{36}$ & 0.184 \\
\hline
\end{tabular}

Table 7. Frontier molecular energies and computed HOMO-LUMO gap (BLYP/DZP)

\begin{tabular}{cccc}
\hline Structure & HOMO energy $(\mathrm{H})$ & LUMO energy $(\mathrm{H})$ & $\mathrm{HL}$ gap $(\mathrm{eV})$ \\
\hline C_rbl_CONH_C=C_C & -0.2095 & -0.1449 & 1.757 \\
C_rbl_CONH_C=C_B & -0.2002 & -0.1409 & 1.613 \\
C_rbl_CONH_C=C_Ar & -0.2113 & -0.1614 & 1.357 \\
C_rbl_CONH_3C=C_Ar & -0.2165 & -0.1919 & 0.669 \\
C_rbl_CONH_G_B_Coja & -0.2104 & -0.1302 & 2.181 \\
C_rbl_CONH_Ar_G_Core & -0.2153 & -0.1813 & 0.925 \\
C_rbl_CONH_C_Core & -0.1998 & -0.1553 & 1.210 \\
\hline
\end{tabular}

range 128-360, while the total bonding energy (TBE), computed per atom, is found between $0.184-0.243 \mathrm{H}$.

The structure of the rhombellanes is given in Figure 1.

Largest differences amongst the energies of the frontier molecular orbitals have been found for the LUMO orbitals; an increase of the LUMO energy of C_rbl_CONH_3C=C_Ar and C_rbl_CONH_Ar_G_Core leads to significant smaller HOMO-LUMO gaps, when compared with the other rhombellanes.

A series of topological parameters, including the polar surface area, the shape attribute and the topological diameter have been computed.

Regarding the results of the docking studies, it can be stated that the fluorine substituted porphyrin (PHR_III) has given the best results, regardless the nanostructure employed as macromolecule.

Table 8. Topological parameters of the rhomebellanes

\begin{tabular}{cccc}
\hline Structure & Polar Surface Area & Shape Attribute & Topological diameter \\
\hline C_rbl_CONH_C=C_C & 774.24 & 250 & 23 bonds \\
C_rbl_CONH_C=C_B & 774.24 & 250 & 23 bonds \\
C_rbl_CONH_C=C_Ar & 774.24 & 250 & 23 bonds \\
C_rbl_CONH_3C=C_Ar & 774.24 & 298 & 27 bonds \\
C_rbl_CONH_G_B_Coja & 1086.48 & 134 & 19 bonds \\
C_rbl_CONH_Ar_G_Core & 872.64 & 102 & 15 bonds \\
C_rbl_CONH_C_Core & 872.64 & 102 & 15 bonds \\
\hline
\end{tabular}

Table 9. The final Lamarckian genetic algorithm docked state - best binding affinities of ligands with the nanostructures

\begin{tabular}{cccccc}
\hline \multirow{2}{*}{ Compound } & \multicolumn{5}{c}{ Binding energies (kcal/mol) } \\
\cline { 2 - 6 } & PHR_I & PHR_II & PHR_III & PHR_IV & PHR_V \\
\hline C_rbl_CONH_C=C_C & -6.0 & -6.0 & -6.9 & -6.0 & -6.0 \\
C_rbl_CONH_C=C_B & -5.9 & -5.9 & -6.9 & -5.8 & -5.9 \\
C_rbl_CONH_C=C_Ar & -5.8 & -5.8 & -7.1 & -5.7 & -5.7 \\
C_rbl_CONH_3C=C_Ar & -7.5 & -7.5 & -9.2 & -5.7 & -5.1 \\
C_rbl_CONH_G_B_Coja & -5.4 & -5.4 & -5.9 & -5.5 & -5.4 \\
C_rbl_CONH_Ar_G_Core & -6.1 & -6.2 & -6.8 & -6.2 & -6.0 \\
C_rbl_CONH_C_Core & -4.2 & -4.3 & -4.7 & -4.4 & -4.4 \\
C60 & -5.4 & -5.4 & -6.0 & -4.9 & -4.9 \\
\hline
\end{tabular}




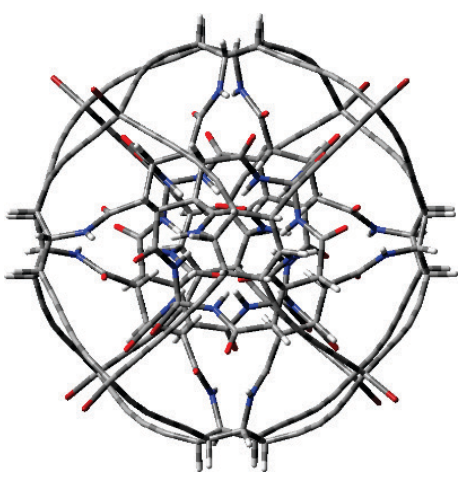

C_rbl_CONH_C=C_C

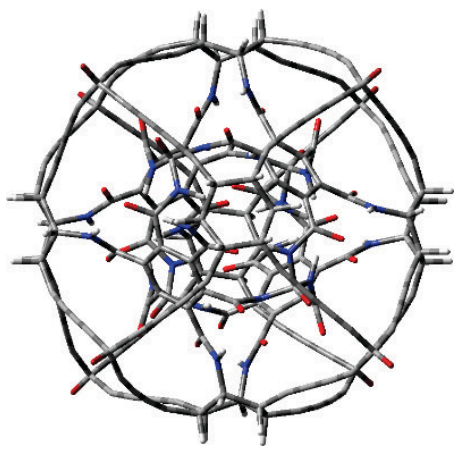

C_rbl_CONH_C=C_Ar

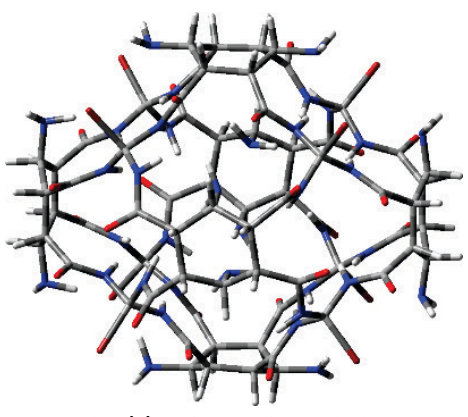

C_rbl_CONH_G_B_Coja

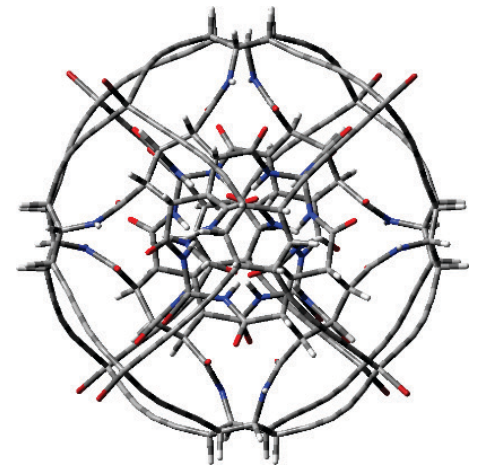

C_rbl_CONH_C $=$ C_B

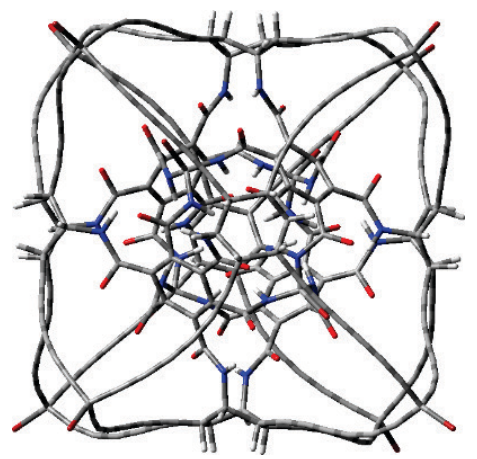

C_rbl_CONH_3C=C_Ar

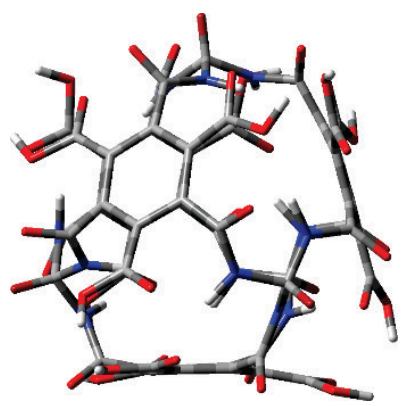

C_rbl_CONH_Ar_G_Core

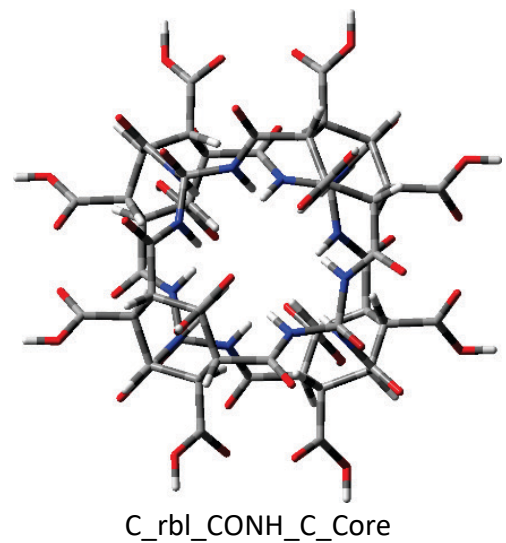

Figure 1. Structures of the investigated rhombellanes. 
Table 10. Calculated constant binding $K_{\mathrm{B}}\left(\times 10^{4}\right)$

\begin{tabular}{|c|c|c|c|c|c|}
\hline \multirow{2}{*}{ Compound } & \multicolumn{5}{|c|}{ Porphyrins } \\
\hline & PHR_I & PHR_II & PHR_III & PHR_IV & PHR_V \\
\hline C_rbl_CONH_C $=$ C_C & 2.52 & 2.52 & 11.5 & 2.52 & 2.52 \\
\hline C_rbl_CONH_C $=$ C_B & 2.12 & 2.12 & 11.5 & 1.79 & 2.12 \\
\hline C_rbl_CONH_C $=$ C_Ar & 1.79 & 1.79 & 16.1 & 1.52 & 1.52 \\
\hline C_rbl_CONH_3C $=$ C_Ar & 31.7 & 31.7 & 559.4 & 1.52 & 0.55 \\
\hline C_rbl_CONH_G_B_Coja & 0.91 & 0.91 & 2.12 & 1.08 & 0.91 \\
\hline C_rbl_CONH_Ar_G_Core & 2.98 & 3.53 & 9.72 & 3.53 & 2.52 \\
\hline C_rbl_CONH_C_Core & 0.12 & 0.14 & 0.28 & 0.17 & 0.17 \\
\hline $\mathrm{C}_{60}$ & 0.91 & 0.91 & 2.52 & 0.39 & 0.39 \\
\hline
\end{tabular}

Table 11. Calculated dissociation constant $K_{D}\left(\cdot 10^{-6}\right)$

\begin{tabular}{|c|c|c|c|c|c|}
\hline \multirow{2}{*}{ Compound } & \multicolumn{5}{|c|}{ Porphyrins } \\
\hline & PHR_I & PHR_II & PHR_III & PHR_IV & PHR_V \\
\hline C_rbl_CONH_C $=$ C_C & 39.77 & 39.77 & 8.71 & 39.77 & 39.77 \\
\hline C_rbl_CONH_C $=$ C_B & 47.10 & 47.10 & 8.71 & 5.57 & 47.10 \\
\hline C_rbl_CONH_C $=$ C_Ar & 55.72 & 55.72 & 6.23 & 66.03 & 66.03 \\
\hline C_rbl_CONH_3C=C_Ar & 3.22 & 3.22 & 0.02 & 66.03 & 182.02 \\
\hline C_rbl_CONH_G_B_Coja & 109.50 & 109.50 & 47.10 & 92.51 & 109.50 \\
\hline C_rbl_CONH_Ar_G_Core & 33.64 & 28.40 & 10.30 & 28.40 & 39.77 \\
\hline C_rbl_CONH_C_Core & 831.0 & 702.05 & 357.05 & 592.70 & 592.70 \\
\hline $\mathrm{C}_{60}$ & 109.50 & 109.50 & 39.77 & 255.02 & 255.02 \\
\hline
\end{tabular}

The interactions between each porphyrin and the corresponding rhombellane structure are discussed below:

(i) C_rbl_CONH_C=C_C, C_rbl_CONH_C=C_B, C_rbl_CONH_C=C_Ar, C_rbl_CONH_3C=C_Ar docking interactions: for all the four porphyrins, the analysis of the docking results show that the only type of interactions is the one of atoms in close-contact. A larger number of atoms in close contact have been observed for the substituted aminoethyl and hydroxyethyl compounds, but does not influence the values of the binding energies;

(ii) C_rbl_CONH_Ar_G_Core: one hydrogen bond $(2.142 \AA)$ is formed between the amino group of PHR_IV and the $\mathrm{C}=\mathrm{O}$ group of the rhombellane; as regards the close contact interactions, the same situation has been observed, a larger number of interactions for the porphyrins substituted with aminoethyl and hydroxyethyl groups.

(iii) C_rbl_CONH_C_Core: all the porphyrins are characterized by the smallest number of atoms in close contact, which is also reflected in the lower binding energies values. Also, two hydrogen bonds are formed, one between the $\mathrm{OH}$ group of porphyrin_ $\mathrm{V}$ and the $\mathrm{C}=\mathrm{O}$ group of the rhombellane (1.994 $\AA$ ), and other between the $\mathrm{NH}_{2}$ of PHR_IV and C=O group of rhombellane (2.003 $\AA$ ).

(iv) C_rbl_CONH_G_B_Coja: three hydrogen bonds are formed between the oxygen atom of PHR_V and the carbonyl groups of rhombellane (2.244 $\AA$, 2.197 $\AA$, 2.128 $)$. Also, two hydrogen bonds have been established between the amino group of PHR_IV and C=O moiety of rhombellane (1.947 ̊̊ and $2.169 \AA$, respectively).

Higher binding energies have been obtained for the interactions of C_rbl_CONH_3C=C_Ar with all of the five substituted porphyrins; the rhombellane has the largest number of atoms and topological diameter within the series. Also, the highest number of hydrogen bonds between a porphyrin and a rhombellane has been obtained for C_rbl_CONH_G_B_Coja, compound that is characterized by the highest value of the polar surface area.

Comparing the docking results of the rhombellanes with the ones obtained for fullerene $C_{60}$, it results that better binding affinities have been obtained for six of the investigated rhombellanes.

Also, the unsubstituted porphyrin (PHR) was employed as ligand and the obtained results of the docking studies are comparable to the ones for the fluorosubstituted compound.

\section{CONCLUSIONS}

The paper has investigated the properties of five substituted porphyrins with amino, hydroxyl, fluoro, aminoethyl and hydroxyethyl groups. In this regard, a series of properties were calculated, such as the difference between singlet and triplet energy states, polarizability, dipole moment, partition coefficient, and steric parameters. 
Table 12. Calculated binding energies and constants for the unsubstituted porphyrin

\begin{tabular}{cccc}
\hline \multirow{2}{*}{ Compound } & \multicolumn{3}{c}{ PHR } \\
\cline { 2 - 4 } & Binding energies $(\mathrm{kcal} / \mathrm{mol})$ & Binding constant $\left(\times 10^{4}\right)$ & Dissociation constant $\left(\times 10^{-6}\right)$ \\
\hline C_rbl_CONH_C=C_C & -6.8 & 9.72 & 10.30 \\
C_rbl_CONH_C=C_B & -6.9 & 11.5 & 8.71 \\
C_rbl_CONH_C=C_Ar & -7.3 & 22.6 & 4.40 \\
C_rbl_CONH_3C=C_Ar & -9.0 & 399.1 & 0.02 \\
C_rbl_CONH_G_B_Coja & -5.5 & 1.08 & 92.50 \\
C_rbl_CONH_Ar_G_Core & -6.4 & 4.94 & 20.23 \\
C_rbl_CONH_C_Core & -4.4 & 0.17 & 592.70 \\
C60 & -6.2 & 3.53 & 28.40 \\
\hline
\end{tabular}

Table 13. Characteristics of the porphyrins with highest affinity for rhombellanes

\begin{tabular}{cccccc}
\hline $\log \mathrm{P}$ & $\Delta S T$ & Dipole moment & Ovality & CAA & CSEV \\
\hline$\sim 0.5$ & $\sim 1.8 \mathrm{eV}$ & $\sim 0$ & $1.45 \div 1.50$ & $280-290 \AA^{2}$ & $245-255 \AA^{3}$ \\
\hline
\end{tabular}

The obtained results showed that the porphyrins with amino groups (PHR_I and PHR_IV) are characterized by the lowest HOMO-LUMO gaps. The steric parameters, as well as the values of polarizability and dipole moment emphasize the division of the five porphyrins into two categories: on the one hand, those substituted with a single group (amino, hydroxy, fluoro), and on the other hand they are the porphyrins with a larger surface accessible to the solvent, but also higher deviation from ovality (hydroxyethyl- and aminoethyl-; PHR_IV and PHR_V).

Lowest values of the binding energies have been obtained for the fluoro-substituted porphyrin (PHR_III), which is most likely due to its hydrophobic character. In good agreement with this assumption are the results obtained for the unsubstituted porphyrin, that has also hydrophobic character.

It may be concluded that the porphyrins with the best results are characterized by the lowest Connolly accessible area and Connolly solvent-excluded volume. They also have the smallest values of ovality (among the series) and positive log $P$.

The main properties of the fluoro- and unsubstituted porphyrin are highlighted in Table 13.

As a result, our future studies will be directed towards the design and investigation of some hydrophobic porphyrins, with decreased values of ovality and solvent accessible surface. As regards the rhombellanes, they are two compounds with better results: $C_{-}$rbl_CONH_3C=C_Ar and C_rbl_CONH_Ar_G_Core. Among the investigated series, the two aforementioned compounds are characterized by the highest values of the LUMO energies. The binding energies outline that six of seven investigated rhombellanes have given better results than fullerene $C_{60}$.
Supplementary Information. Supporting information to the paper is attached to the electronic version of the article at: https://doi.org/10.5562/cca3789.

PDF files with attached documents are best viewed with Adobe Acrobat Reader which is free and can be downloaded from Adobe's web site.

\section{REFERENCES}

[1] R. R. Allison. Future Oncol. 2014, 10(1), 123. https://doi.org/10.2217/fon.13.176

[2] T. Kushibiki, T. Hirasawa, S. Okawa, M. Ishihara. J. Healthc. Eng. 2013, 4(1), 87. https://doi.org/10.1260/2040-2295.4.1.87

[3] J. Zhang, C. Jiang, J. P. Longo, R. B. Azevedo, H. Zhang, L. A. Muehlmann. Acta Pharm. Sinica B. 2018, 8(2), 137. https://doi.org/10.1016/j.apsb.2017.09.003

[4] E. Caruso, M. Cerbara, M. C. Malacarne. J. Photochem. Photobiol. B. 2019, 195, 39-50.

https://doi.org/10.1016/j.jphotobiol.2019.04.010

[5] S. Kwiatkowski, B. Knap, D. Przystupski, J. Saczko, E. Kedzierska, K. Knap-Czop, J. Kotlinska, O. Michel, K. Kotowski, J. Kulbacka. Biomedicine \& Pharmacotherapy. 2018, 106, 1098 https://doi.org/10.1016/j.biopha.2018.07.049

[6] Y. Matoba, K. Banno, I. Kisu, D. Aoki. Photodiagnosis Photodyn. Ther. 2018, 24, 52.

https://doi.org/10.1016/j.pdpdt.2018.08.014

[7] Y. Ju, B. Dong, J. Yu. Nano Today. 2019, 26, 108. https://doi.org/10.1016/j.nantod.2019.03.006

[8] G. Lan, K. Ni, W. Lin. Coord. Chem. Rev. 2019, 379, 65. https://doi.org/10.1016/j.ccr.2017.09.007

[9] R. Chandra, M. Tiwari, P. Kaur, M. Sharma, R. Jain, S. Dass. Indian J. Clin. Biochem. 2000, 15, 183. https://doi.org/10.1007/BF02867558 
[10] B. Mansoori, A. Mohammadi, M. A. Doustvandi. Photodiagnosis Photodyn. Ther. 2019, 26, 395. https://doi.org/10.1016/j.pdpdt.2019.04.033

[11] M. Y. Yang, R. R. Zhao, Y. F. Fang. Int. J. Pharm. 2019, 570, 118663.

https://doi.org/10.1016/j.ijpharm.2019.118663

[12] P. C. Calses, J. J. Crawford, J. R. Lill. Trends in Cancer. 2019, 5, 5 . https://doi.org/10.1016/j.trecan.2019.04.001

[13] A. T. Gomes, M. Neves, J. Cavaleiro. Anais da Academia Brasileira de Ciências. 2018, 90, 993. https://doi.org/10.1590/0001-3765201820170811

[14] A. E. O'Connor, W. M. Gallagher, A. T. Byrne. Photochem. Photobiol. 2009, 85, 1053.

[15] K. Shanmugapriya, H. W. Kang. Materials Sci. Eng. C, 2019. 105, 110110.

https://doi.org/10.1016/j.msec.2019.110110

[16] L. P. Roguin, N. Chiarante, M. C. García Vior. Int. J. Biochem. Cell Biol. 2019, 114, 105575. https://doi.org/10.1016/j.biocel.2019.105575

[17] M. Kaleta-Richter, A. Kawczyk-Krupka, D. Aebisher. Photodiagnosis Photodyn. Ther. 2019, 25, 253. https://doi.org/10.1016/j.pdpdt.2019.01.004

[18] M. Rizwan, T. Rasheed, A. Raza. J. Drug Del. Sci. Technol. 2019, 51, 70. https://doi.org/10.1016/j.jddst.2019.02.014

[19] K. Albert, H. Y. Hsu. Molecules 2016, 21, 1585. https://doi.org/10.3390/molecules21111585

[20] H. Abrahamse, M. R. Hamblin. Biochem. J. 2016, 473(4), 347. https://doi.org/10.1042/BJ20150942
[21] A. Escudero, C. Carrillo-Carrio, M. C. Castillejos, E. Romero-Ben, C. Rosales-Barrios, N. Khiar. Mater. Chem. Front., 2021, 5, 3788. https://doi.org/10.1039/D0QM00922A

[22] P. Sundaram, H. Abrahamse. Materials 2020, 13, 4830.

https://doi.org/10.3390/ma13214830

[23] M. V. Diudea. Iranian J. Math. Chem. 2018, 9(1), 1.

[24] M. E. Zandler, F. D'Souza. C. R. Chimie 2006, 9, 960. https://doi.org/10.1016/j.crci.2005.12.008

[25] Y. B. Wang, Z. Lin. J. Am. Chem. Soc. 2003, 125, 6072. https://doi.org/10.1021/ja028998g

[26] ADF2014, SCM, Theoretical Chemistry. Vrije Universiteit, Amsterdam, The Netherlands. http://www.scm.com.

[27] S. J. A. van Gisbergen, J. G. Snijders, E. J. Baerends. J. Chem Phys. 1995, 103, 9347. https://doi.org/10.1063/1.469994

[28] S. J. A. van Gisbergen, J. G. Snijders, E. J. Baerends. Comp. Phys. Commun. 1999, 118, 119. https://doi.org/10.1016/S0010-4655(99)00187-3

[29] E. van Lenthe, E. J. Baerends. J. Comput. Chem. 2003, 24, 1142. https://doi.org/10.1002/jcc.10255

[30] Y. Zyrianov. J. Chem. Inf. Model. 2005, 45, 657. https://doi.org/10.1021/ci050005।

[31] M. L. Connolly, J. Am. Chem. Soc. 1985, 107, 1118. https://doi.org/10.1021/ja00291a006

[32] O. Trott, A. J. Olson. J. Comput. Chem. 2010, 31, 455.

[33] M. V. Diudea. Int. J. Chem. Model. 2018, 9(2-3), 1. 